\title{
MEASURING THE EFFECTS OF MOZART'S MUSIC ON ADULT AUDIENCE
}

\author{
Stela Drăgulin ${ }^{1}$, Fulvia Anca Constantin ${ }^{2 *}$ \\ ${ }^{1}$ Transilvania University, Braşov, 501111, Romania \\ Academy of Romanian Scientists - AOSR, Assoc. Member \\ ${ }^{2}$ Transilvania University, Braşov, 501111, Romania \\ *fulvia.constantin@gmail.com
}

\section{Introduction}

The effect of Mozart's music was long debated. On one side there were the views claiming that a child is getting smarter for just listening to music. On the other side were situated the neuroscientists who explained how music (not necessary Mozart's music) can and does really impact brain development and cognition. The aim of this paper is to show from a different perspective if Mozart's effect is a myth or a reality. We look to find answers on this by measuring the effect of Mozart's music on adult audience with the help of MindWave device headset.

\section{Overview on Findings about Mozart's Music Effect}

The arguments included in the overview present pro and cons opinions on the effect produced by listening to Mozart's music.

Arguments on "Mozart Effect"

The concept described as "Mozart effect" was explained by dr. Tomatis in 1991, while he looked in solutions for dyslexia, autism and other learning disorders. He used Mozart's music to prove that different frequencies helped the ear and favored healing and the improvement of the brain performance. [1]

Two years later, F. Rauscher et al. found a momentary improvement of spatial-reasoning after playing a part of Mozart Piano Sonata. Though, the study didn't make any statement of an increase in IQ in general.[2]

In time, there were researchers on music therapy proving that while any kind of music has an effect on us, Mozart's music is more directly. It is clear, organized, efficient and not very emotional. It penetrates the psyché and body at the same time in a subtle and powerful way. Dr. Campbell, an international authority in the relationship music - education medicine showed that music is not only an unique aesthetic experience, but also a resource for a more creative, intelligent, and healthier life.[3] In another study it has been investigated the electrical discharge patterns of the brain areas after experiencing Mozart music. For example, listening about ten minutes of Mozart's sonata K448 not only presents an enhanced synchrony of the patterns of the right and left areas of the brain, but also an increased power of the beta spectrum of the electroencephalogram.[4] Moreover, a notable sign of the existence of Mozart effect was seen in epilepsy proved by the fact that auditioning Mozart indicated a significant decrease in epileptiform activity. [5]

Regarding the stress, the main concern of the present, one of the methods implying relaxation is listening to music. Though, the music offered to reduce stress is often too slow, almost sedative, leading to a passive state with drowsy tendencies. This is not necessarily the best choice of relaxing and restoring oneself. As a better choice, Mozart's music is light and fine, an effective tool for a conscious and creative relaxation used against the overstimulation of the brain and an over activity of the body.

And even if Mozart is not the favourite composer for all, or if classical music is not the first of the preferences, his music (simple and concise) creates a positive atmosphere good for learning, relaxation and creation at full potential.

\section{Arguments against "Mozart Effect"}

In 2010 it was conducted an analysis that combined the results of 40 studies on the subject of the existence of the Mozart Effect. The authors concluded that there is slight evidence to sustain it, the 
effect sizes being small.[6] Also, the reproduction of Rauscher and Shaw's 1993 experiment proved the original findings statistically insignificant.[7] Moreover, in other opinions, Mozart Effect is just an object of arousal and heightened mood, [8] [9] there is no direct evidence for improvement of overall intelligence and no influence on spatial cognition.

\section{The Actual Research}

We structured the research information on three levels: description of the device used for measuring the actual effect of Mozart's music on the level of relaxation, the experiment and the obtained results.

\subsection{The Neurosky MindWave}

The Neurosky MindWave (Figure 1) is a device used to register and keep track of the electrical signals caused by neural activity in the brain. It could be used easily and in any circumstance regarding the user (lying down, sitting, dancing, more or less healthy). Regarding the device, it is needed a laptop with internet/ Bluetooth connection.

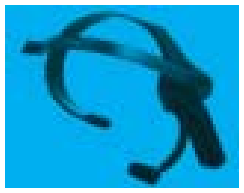

Figure 1. MindWave Headset

MindWave device evaluates the user's brain waves, precisely the raw signals, the EEG power spectrum, and the eSense meters for attention (concentration) and meditation (relaxation) during a certain task. The interface of the MindWave headset as it appears on the screen can be seen below. (Figure 2) [10]

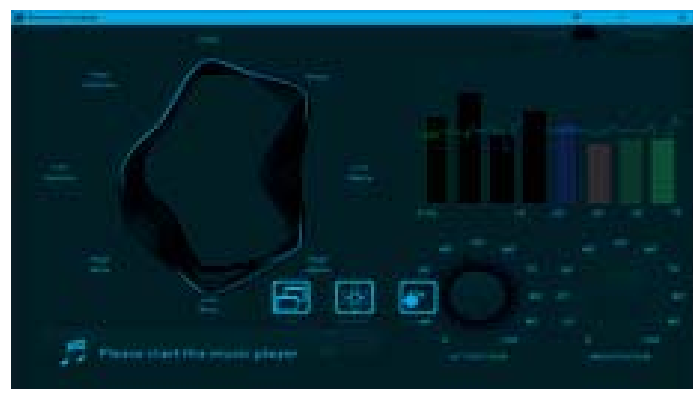

Figure 2. MindWave Headset Interface
The user could make any activity during the registration the movement not changing the actual result. Data is expressed in terms of frequency. The levels of attention/ concentration and meditation/ relaxation are obtained by comparing mean scores when listening to music.

The EEG band frequencies and their basic characteristics are shown in Table 1 as appear on the description of the program.

Table 1. EEG band frequencies and their characteristics

\begin{tabular}{|l|l|l|}
\hline $\begin{array}{l}\text { Brainwave Fre- } \\
\text { quency Range }\end{array}$ & $\begin{array}{l}\text { Characteris- } \\
\text { tics of mental } \\
\text { stage }\end{array}$ & $\begin{array}{l}\text { Associated } \\
\text { colour }\end{array}$ \\
\hline $\begin{array}{l}\text { Delta } \\
(0-4 \mathrm{~Hz})\end{array}$ & $\begin{array}{l}\text { Deep sleep, } \\
\text { unconscious }\end{array}$ & red \\
\hline $\begin{array}{l}\text { Theta } \\
(4-8 \mathrm{~Hz})\end{array}$ & $\begin{array}{l}\text { Deep relax- } \\
\text { ation }\end{array}$ & orange \\
\hline $\begin{array}{l}\text { Low Alpha } \\
(8-10 \mathrm{~Hz})\end{array}$ & $\begin{array}{l}\text { Wakeful } \\
\text { relaxation, } \\
\text { conscious }\end{array}$ & yellow \\
\hline $\begin{array}{l}\text { High Alpha } \\
(10-12 \mathrm{~Hz})\end{array}$ & $\begin{array}{l}\text { Increased self- } \\
\text { awareness }\end{array}$ & green \\
\hline $\begin{array}{l}\text { Low Beta } \\
(12-18 \mathrm{~Hz})\end{array}$ & $\begin{array}{l}\text { Active think- } \\
\text { ing, attention }\end{array}$ & light blue \\
\hline $\begin{array}{l}\text { High Beta } \\
(18-30 \mathrm{~Hz})\end{array}$ & $\begin{array}{l}\text { Mental activ- } \\
\text { ity, alertness }\end{array}$ & navy blue \\
\hline $\begin{array}{l}\text { Low Gamma } \\
(30-50 \mathrm{~Hz})\end{array}$ & $\begin{array}{l}\text { Cognitive } \\
\text { processing, } \\
\text { senses, intel- } \\
\text { ligence }\end{array}$ & violet \\
\hline $\begin{array}{l}\text { High Gamma } \\
(50-70 \mathrm{~Hz})\end{array}$ & $\begin{array}{l}\text { Cognitive } \\
\text { tasks such as } \\
\text { memory }\end{array}$ & bright purple \\
\hline
\end{tabular}

\subsection{The experiment}

The research focuses on measuring the level of attention and concentration of the audience listening to Mozart's music. A number of three listeners of different ages, backgrounds and health statuses, having or not a musical background, who listened more or less frequently Mozart, were included in the research lot. The music (CDs of quality) had been chosen based on the musical characteristics (melody, harmony, rhythm and timbre - instrumental and/ or vocal). We also avoid the music works listened by 
the subjects in daily basis, careful of the influence this fact could have on the experiment.

The measurements were done carefully, one person/ one audition at the time, except for the last audition of the two opera fragments which were listened together with a pause of fifteen minutes between them. The reception of music was done in a relaxing and free of stressors environment. The listener sat down relaxed, only listening to music. We gave the subject information about the experiment assuring the subject to feel free to use his imagination, to behave as he feels at the moment. The list of music includes 8 works of different categories:

1. Piano Concerto No. 21 in C major, K. 467 (Andante)

2. Symphony No. 40 in G minor, K. 550 (Molto Allegro)

3. Sonata for Two Pianos in D major, K. 448/375a (Molto Allegro)

4. Violin Concerto No. 3 in G major, K. 216 (Allegro)

5. Serenade No. 13 for string quartet and bass in $G$ major, "Eine kleine Nachtmusik", K. 525 (RondoAllegro)

6. Concerto for Flute, Harp and Orchestra in C major, K. 299 (Andantino)

7. The Magic Flute, Queen of the Night

8. The Marriage of Figaro, Non Piu Andrai

\subsection{Results}

During the music session the listeners showed an increase in either their levels of concentration or relaxation, depending on the music work they listened to. Once the music ended, on the screen appeared the brainwave frequency type describing ranges of activity, due to eSense calculation. [11]

Although we measured the mental activity, psychological factors such as mood or tiredness were considered only theoretically.

The steps taken in the session are described briefly below:

- Set MindWave headset and connect to the laptop via Bluetooth.

- Listen to iTUNE / mp3 music

- Whenever the music stops, the software shows the average value at the end of the software, making a qualitative estimate of the test. This estimate materializes as the corresponding color.
In our experiment the comparison between the subjects showed a variety of data. Although both heart rate and attention and meditation values could be tracked, the interpretation of the results focused on the main outcomes. These showed diversity, even if there were cases when two responses were similar. Moreover, listening to the first movements of Sonata for Two Pianos in D major and Concerto for Flute, Harp and Orchestra in C major showed consistency. The same answer for all listeners appeared on the screen. We considered it interesting, on one hand unusual since the subjects were of different ages and interests on the other hand we had the proof the Mozart Effect works.

Table 2 includes the results. We noted the similarity and, also, the differences between the results. We have also found differences in the behavior of the audience. If one subject was "vocal" keeping the rhythm with his foot and waving the arm as a conductor of orchestra, the other two subjects were low on moving and extremely quiet. The expression on their faces explained the feelings of the moment, a deep concentration, pleasure, sadness, tiredness, so on. In order to keep them anonymous the subjects were noted with X, Y and Z.

Table 2. Example of the results

\begin{tabular}{|c|c|c|c|}
\hline $\begin{array}{l}\text { Mfisic } \\
\text { Work } \\
\text { Listened }\end{array}$ & $\frac{\text { Result }}{\mathbf{X}}$ & $\underset{\mathbf{Y}}{\text { Result }}$ & $\frac{\text { Result }}{\mathbf{Y}}$ \\
\hline 1 & Theta & $\begin{array}{l}\text { Low } \\
\text { Alpha }\end{array}$ & $\begin{array}{l}\text { High } \\
\text { Alpha }\end{array}$ \\
\hline 2 & $\begin{array}{l}\text { Low } \\
\text { Gamma }\end{array}$ & $\begin{array}{l}\text { High } \\
\text { Alpha }\end{array}$ & $\begin{array}{l}\text { Low } \\
\text { Gamma }\end{array}$ \\
\hline 3 & $\begin{array}{l}\text { High } \\
\text { Beth }\end{array}$ & $\begin{array}{l}\text { High } \\
\text { Beth }\end{array}$ & $\begin{array}{l}\text { High } \\
\text { Beta }\end{array}$ \\
\hline 4 & $\begin{array}{l}\text { High } \\
\text { Gamma }\end{array}$ & $\begin{array}{l}\text { Low } \\
\text { Gamma }\end{array}$ & $\begin{array}{l}\text { High } \\
\text { Beta }\end{array}$ \\
\hline 5 & $\begin{array}{l}\text { High } \\
\text { Alpha }\end{array}$ & $\begin{array}{l}\text { Low } \\
\text { Gamma }\end{array}$ & $\begin{array}{l}\text { Low } \\
\text { Beta }\end{array}$ \\
\hline 6 & $\begin{array}{l}\text { Low } \\
\text { Beta }\end{array}$ & $\begin{array}{l}\text { Low } \\
\text { Beta }\end{array}$ & $\begin{array}{l}\text { Low } \\
\text { Beta }\end{array}$ \\
\hline 7 & $\begin{array}{l}\text { High } \\
\text { Beta }\end{array}$ & $\begin{array}{l}\text { High } \\
\text { Betan }\end{array}$ & $\begin{array}{l}\text { Low } \\
\text { Gamma }\end{array}$ \\
\hline 8 & $\begin{array}{l}\text { Low } \\
\text { Beta }\end{array}$ & $\begin{array}{l}\text { Low } \\
\text { Gamma }\end{array}$ & $\begin{array}{l}\text { High } \\
\text { Beta }\end{array}$ \\
\hline
\end{tabular}


The results were saved for a further comparison. We recognized at the moment that the experiment needed more improvement, but we got satisfied with the measuring done with the Mindwave device.

Asking the subjects about their experience, all of them got satisfied and ready to continue the experiment. Apart from the outcome their mood improved, got more relaxed and let their minds to dream, to become creative.

\section{Conclusion}

Although our research is an evidence for mainly positive results regarding the effects of Mozart's music on the level of concentration and emotions, we continue the research for further stronger findings. First of all, we will add a higher number of listeners, subjects of the research. Second, we will include more of Mozart music works, and third, we will repeat the measuring being more careful at their mood. It will also be necessary to develop a LabVIEW application meant to integrate all data in one multimedia platform and to perform a deeper statistical analysis together with a higher number of recorded signals from other various types of sensors.

In our case we plot the BrainWaves medium values (Delta, Theta, Low Alpha etc., see Fig.1) with reported percent relative to the highest level (considered $100 \%$ ) and in the same times the maxim and medium values of attention and meditation index. All this parameters were calculated and plotted with the intention to see and monitor the effects of music therapy.

\section{References}

[1] Rauscher, F, H. Shaw G.L., Ky, K.N. B.M. Thompson, S.R. Andrews, An Historical Commentary on the Physiological Effects of Music: Tomatis, Mozart and Neuropsychology. Integrative Physiological and Behavioral Science 35. (2000). 174.

[2] F.H. Rauscher et al., Nature. 365. (1993). 611. Music and Spatial Task Performances. Nature. 365. (1993). 611.

[3] Sarnthein J, von Stein A, Rappelsberger P, et al. Persistent Patterns of Brain Activity: an EEG Coherence Study of the Positive Effect of Music on Spatialtemporal Reasoning. Neurol Res (1997) 19. 107.

[4] Hughes JR, Daaboul Y, Fino JJ, et al. The Mozart effect on Epileptiform activity. Clin Electroencephalogram 29. (1999). 109.

[5] Campbell, D. The Mozart Effect: Tapping the Power of Music to Heal the Body, Strengthen the Mind, and Unlock the Creative Spirit (2001)

[6] J. Pietschning, M. Voracek, M. Foreman, K. Anton. Mozart Effect-Shmozart Effect: A MetaAnalysis. Intelligence, 38. (2010). 314.

[7] Chabris, C.F., Prelude or requiem for the Mozart effect?. Nature. 400. (1999). 827.

[8] K.M. Steele, Arousal and Mood Factors for the Mozart effect. Perceptual and Motor Skills. 91 (2000). 188

[9] M.H. Jones, S.D. West, D. B. Estell. The Mozart Effect: Arousal, preference, and spatial performance Psychology of Aesthetics, Creativity, and the Arts. S (2006). 26

[10] https://store.neurosky.com/pages/mindwave (2017)

[11] https://store.neurosky.com/pages/mindwave (2017) - screen details. 